\title{
Interplay between the morphometry of the lungs and the mode of locomotion in birds and mammals
}

\author{
DANIELA FIGUEROA ${ }^{1}$, RICARDO OLIVARES $^{1}$, MICHEL SALABERRY $^{2}$, \\ PABLO SABAT ${ }^{2,3}$ and MAURICIO CANALS ${ }^{2, *}$
}

\author{
${ }^{1}$ Departamento de Ciencias Biológicas Animales. Facultad de Ciencias Veterinarias y Pecuarias. \\ ${ }^{2}$ Departamento de Ciencias Ecológicas. Facultad de Ciencias. Universidad de Chile. Casilla 653. Santiago. \\ Chile. E-mail: mcanals@uchile.cl \\ ${ }^{3}$ Center for Advanced Studies in Ecology \& Biodiversity, Departamento de Ecología, Facultad de Ciencias \\ Biológicas, Pontificia Universidad Católica de Chile, Santiago
}

\begin{abstract}
We studied the lung diffusion parameters of two species of birds and two species of mammals to explore how structural and functional features may be paralleled by differences in life style or phylogenetic origin. We used two fast-flying species (one mammal and one bird), one running mammal and one bird species that flies only occasionally as models. The harmonic mean thickness of the air-blood barrier was very thin in the species we studied. An exception was the Chilean tinamou Notoprocta perdicaria, which only flies occasionally. It showed an air-blood barrier as thick as that of flightless Galliformes. We found that the respiratory surface density was significantly greater in flying species compared to running species. The estimated values for the oxygen diffusion capacity, $\mathrm{D}_{\mathrm{t}} \mathrm{O}_{2}$ follow the same pattern: the highest values were obtained in the flying species, the bat and the eared dove. The lowest value was in N. perdicaria.

Our findings suggest that the studied species show refinements in their morphometric lung parameters commensurate to their energetic requirements as dictated by their mode of locomotion, rather than their phylogenetic origin. The air-blood barrier appears to be thin in most birds and small mammals, except those with low energetic requirements such as the Chilean tinamou. In the species we studied, the respiratory surface density appears to be the factor most responsive to the energetic requirements of flight.
\end{abstract}

Key terms: diffusing capacity, lungs, flight.

\section{INTRODUCTION}

The morphology and the efficiency of respiratory organs correspond with the oxygen requirements of animals. Flying animals, such as birds, insects and bats, which have high aerobic capacities, appear to have the most efficient respiratory organs (Maina, 2000a; Maina and King, 1984; Maina et al., 1991).

Among extant vertebrates, flight evolved independently in birds and bats. According to their phylogenetic and morphological differences, the strategies to accomplish this energetically expensive form of locomotion appear to be different (Maina, 1998). Birds exchange gas through a process in which a wide range of pulmonary and extrapulmonary factors are integrated, operating sub-maximally (a broad-based low-keyed strategy); bats, however, appear to have a restricted number of factors operating close to their maximal levels (a narrow-based high-keyed strategy) (sensu Maina, 1998), probably related to the mammalian lung design that they possess.

Of all components of the respiratory chain, pulmonary diffusion is the only variable that exclusively depends upon morphometric intrapulmonary parameters (Weibel et al., 1991), providing an excellent model to study of the structural optimization of the lung. Oxygen flow is

* To whom all correspondence should be addressed. 
directly related to the oxygen partial pressure gradient between the alveoli and blood capillaries, and the oxygen diffusion capacity $\left(\mathrm{D}_{\mathrm{O} 2}\right)$ (Weibel, 1970/71; Maina, 2002a). The latter is determined by the ratio between the respiratory surface area (AA) and the harmonic mean thickness of the air-blood barrier $\left(\tau_{\mathrm{h}}\right)$ (Weibel, 1970/ 71; Gehr et al., 1981; Maina et al., 1982; Maina and King, 1984; Maina et al., 1991; Maina and Nathaniel, 2001; Maina, 2002a). Since AA may be expressed as the product of the volume of the exchange lung tissue $\left(\mathrm{V}_{\mathrm{LE}}\right)$, the respiratory surface density $\left(A S_{d}\right)$, and Krogh's permeation coefficient $(\kappa)$ (Gehr et al., 1981; Maina, $2002 \mathrm{a})$ the oxygen conductance $\left(\mathrm{D}_{\mathrm{O} 2}\right)$ may only be modified by changes in $\mathrm{V}_{\mathrm{LE}}, \mathrm{AS}_{\mathrm{d}}$ or $\tau_{\mathrm{h}}: D_{O 2}=\kappa \frac{A S_{d} \cdot V_{L E}}{\tau_{h}}$.

There is evidence that birds and bats have different methods to optimize oxygen flow. For example, the respiratory surface density of bats appears to be only slightly lower than that of non-flying mammals, but much lower than that of birds. Also, the harmonic mean thickness of the blood-gas barrier in bats is slightly thinner than that of non-flying mammals, yet thicker than that of birds (Maina, 2000b). In birds, the lung volume is lower than that of non-flying mammals, while bat lungs show the opposite trend. Although a high respiratory surface density and a thin air-blood barrier have been reported in several small bird species, such as Colibri coruscans (Dubach, 1981), most birds have similar values of respiratory surface density and thickness of the bloodgas barrier (Maina, 2002a). However, the Orders containing non-flying birds or birds that fly occasionally (e.g., Galliformes, Struthioformes and Sphenisciformes), appear to have a thicker blood-gas barrier (Maina, 2002a).

We studied the lung diffusion parameters of two species of birds and two species of mammals to explore how structural and functional features may be paralleled by differences in life style (running or flying) or phylogenetic origin (mammal or bird). To do this, two fast- flying species (one mammal and one bird), one running mammal and one bird species that flies only occasionally were used as models.

\section{MATERIAL AND METHODS}

We used the Leaf-eared mouse Phyllotis darwini (Rodentia: Muridae) as our running mammal model $\left(\mathrm{n}=3 ; \mathrm{M}_{\mathrm{b}}=75.36 \pm 4.96 \mathrm{~g}\right.$ where $\mathrm{M}_{\mathrm{b}}$ is the body mass: $\bar{x} \pm 1 s d$ ), a rodent dwelling in grasslands, scrub, open forest and rocky areas. Our flying mammal model was the Mouse-eared bat Myotis chiloensis (Chiroptera: Vesperilionidae) (n $\left.=3 ; \mathrm{M}_{\mathrm{b}}=6.05 \pm 0.10 \mathrm{~g}\right)$, a small bat inhabiting thickets near watercourses. The bird models were 1) the Eared dove Zenaida auriculata (Columbiformes: Columbidae) $(\mathrm{n}=3 ; 141.1 \pm 1.55 \mathrm{~g})$, a common fast-flying bird which inhabits farm lands and urban zones from the coast to the Andes foothills; and 2) the Chilean tinamou Nothoprocta perdicaria $(\mathrm{n}=3$; $398.33 \pm 11.70 \mathrm{~g}$ ), an endemic species with a chubby body and short wings dwelling in grasslands, thickets and farmland. This species usually runs between shrubs and only occasionally makes short flights.

Three adult individuals of each species were captured with mist nets or Shermann traps in central Chile during March, 2004. After capture, animals were weighed, killed by an overdose of anesthetic by intraperitoneal injection, dissected and the trachea were exteriorized and cannulated. In the case of birds we avoided injection into the air sacs. A quantity of $2.3 \%$ glutaraldehyde in phosphate buffer (ph 7.4) was introduced in the trachea (Maina 2002a). When the fixative solution exceeded the level of the trachea, we closed it and tied it to the cannula. Immediately following this procedure, the lungs were removed and immersed in the same fixative at $4{ }^{\circ} \mathrm{C}$ for a minimum of 2 hours. Next, tissues (right and left lungs) were processed for routine electronic transmission microscopy. Briefly, two pieces of 1-2 mm thickness were obtained from each lobe in mammals and four randomly chosen pieces were obtained from each lung of birds. The 
pieces were washed with buffer and postfixed with $1 \%$ osmium tetroxide for 1 hour at $4{ }^{\circ} \mathrm{C}$. Tissues were then dehydrated in graded concentrations of alcohol and infiltrated and embedded in epoxy resin constructing cubes of $2-3 \mathrm{~mm}^{3}$, obtaining semi-thin VUR sections of $1 \mu \mathrm{m}$. Tissue samples were stained with $1 \%$ toluidine blue. Ultrathin sections of $60-90 \mathrm{~nm}$ of thickness were made and mounted on copper mesh grids. These sections were contrasted with lead citrate. Sections were studied through optical and transmission electron microscopy (JEOL/JEM 100SX). Eight to twelve sections were photographed, digitalized and twelve semithin and twelve ultra-thin sections per individual were analyzed using Scion Image Software.

The respiratory surface density $\left(\mathrm{AS}_{\mathrm{d}}\right)$ was estimated by means of line-intersection stereologic method (Weibel, 1970/71): $A S_{d}=\frac{2 N}{1 / 2 \cdot P_{T} \cdot Z}$, where $\mathrm{N}$ is the number of intersections between line probes of length $\mathrm{Z}$ with the respiratory surface and $\mathrm{P}_{\mathrm{T}}$ is the number of test points (Figure 1).

The harmonic mean thickness of the airblood barrier $\left(\tau_{h}\right)$ was estimated by a stereologic method in a square lattice grid as suggested by Weibel (1970/71) and Maina (2002a): $\frac{1}{\tau_{h}}=\frac{3}{2} \cdot \frac{\sum_{j=1}^{m} f_{j} \cdot \frac{1}{l_{j}}}{\sum_{j=1}^{m} f_{j}}$, where $\mathrm{l}_{\mathrm{j}}$ is the mid-value of intercept length of linear probes, $f_{j}$ the frequency of class $j$ and $m$ the number of classes (Figure 2).

The factor effects (taxa and locomotion type) on $\tau_{\mathrm{h}}$ and $\mathrm{AS}_{\mathrm{d}}$ were analyzed with a two-way repeated measures ANOVA. Multiple comparisons were performed with Tukey's test.

\section{RESULTS}

The respiratory surface density was different between mammals and birds $\left(\mathrm{F}_{6,3}\right.$ $=123,2, \mathrm{p}<0.01)$ and between flying species and running or occasionally flying species $\left(\mathrm{F}_{6,3}=114,9, \mathrm{p}<0.01\right)$. The interaction between taxa and locomotion type was not significant $\left(\mathrm{F}_{6,3}=6.59\right)$. The $a$ posteriori Tukey analyses showed that these differences were sustained by differences between the flying bird $Z$. auriculata and the running mammal $P$. darwini. The former has a higher $\mathrm{AS}_{\mathrm{d}}$, therefore, the difference between birds and mammals appears to be only a consequence of the high $\mathrm{AS}_{\mathrm{d}}$ of $Z$. auriculata. However, differences among locomotion types appear to be well sustained (Table1 and Figure 3 ).

The harmonic mean thickness also showed a significant effect of taxa $\left(\mathrm{F}_{6,3}=\right.$ $19.15, \mathrm{p}<0.01)$, locomotion type $\left(\mathrm{F}_{6,3}=\right.$ $26.89, \mathrm{p}<0.01)$ and interaction $\left(\mathrm{F}_{6,3}=\right.$ $29.52 ; \mathrm{p}<0.01)$. However, multiple comparisons revealed that these differences were only sustained by the thicker air-blood barrier observed in $N$. perdicaria (Figure 4).

\section{DISCUSSION}

The oxygen diffusion capacity $\left(\mathrm{D}_{\mathrm{O} 2}\right)$ may be estimated from morphometric information as a theoretical capacity determined by the exchange surface and the tissue barrier (Weibel et al., 1991). Regarding only the tissue component, the tissue oxygen diffusion capacity $\left(\mathrm{D}_{\mathrm{t}} \mathrm{O}_{2}\right)$ from air to plasma is determined by the harmonic mean thickness of the air-blood barrier $\left(\tau_{\mathrm{ht}}\right)$, the most appropriate estimator of the conductance (Weibel and Knight, 1964; Weibel, 1970/71), the respiratory surface density $\left(\mathrm{AS}_{\mathrm{d}}\right)$ and the lung volume $\left(\mathrm{V}_{\mathrm{L}}\right)$. In this study we only analyzed $\tau_{\mathrm{ht}}$ and $\mathrm{AS}_{\mathrm{d}}$.

Lungs of small birds with high massspecific metabolisms (Novoa 2003) exhibit different morphometric refinements (Maina 2000a). For instance, the order Passeriformes, a group that includes $60 \%$ of extant bird species, possess more efficient lungs compared to non-passerine species. In contrast, soaring and gliding birds, need less energy during flight and appear to have relatively less efficient lungs (Vitali and Richardson, 1998; Maina, 2000a; 2002a). 


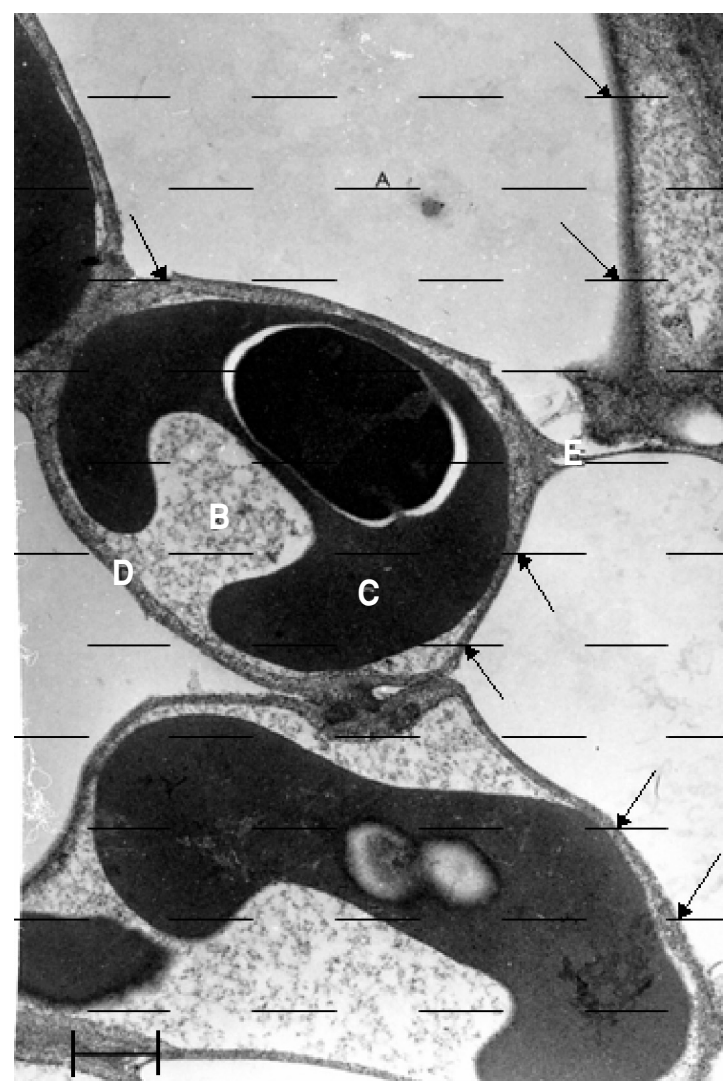

Fig. 1: Electron micrograph of gas exchange tissue of Zenaida auriculata. 3000X with a test line system to estimate respiratory surface

$2 N$

density $\left(\mathrm{AS}_{\mathrm{d}}\right): A S_{d}=\frac{}{1 / 2 \cdot P_{T} \cdot Z}$, where $\mathrm{N}$ is the $1 / 2 \cdot P_{T} \cdot Z$

number of intersections between line probes of length $\mathrm{Z}$ with the respiratory surface and $\mathrm{P}_{\mathrm{T}}$ is the number of test points. Each line with two test points, thus $1 /{ }_{2} \mathrm{P}_{\mathrm{T}} \mathrm{Z}$ represents the length of the total test line system. Arrows mark some intersections. A: Air capillaries. B: Blood capillaries. C: Erythrocytes. D: Air-blood barrier. E: Tissue not involved in gas exchange. Scale bar, $0.5 \mu \mathrm{m}$.

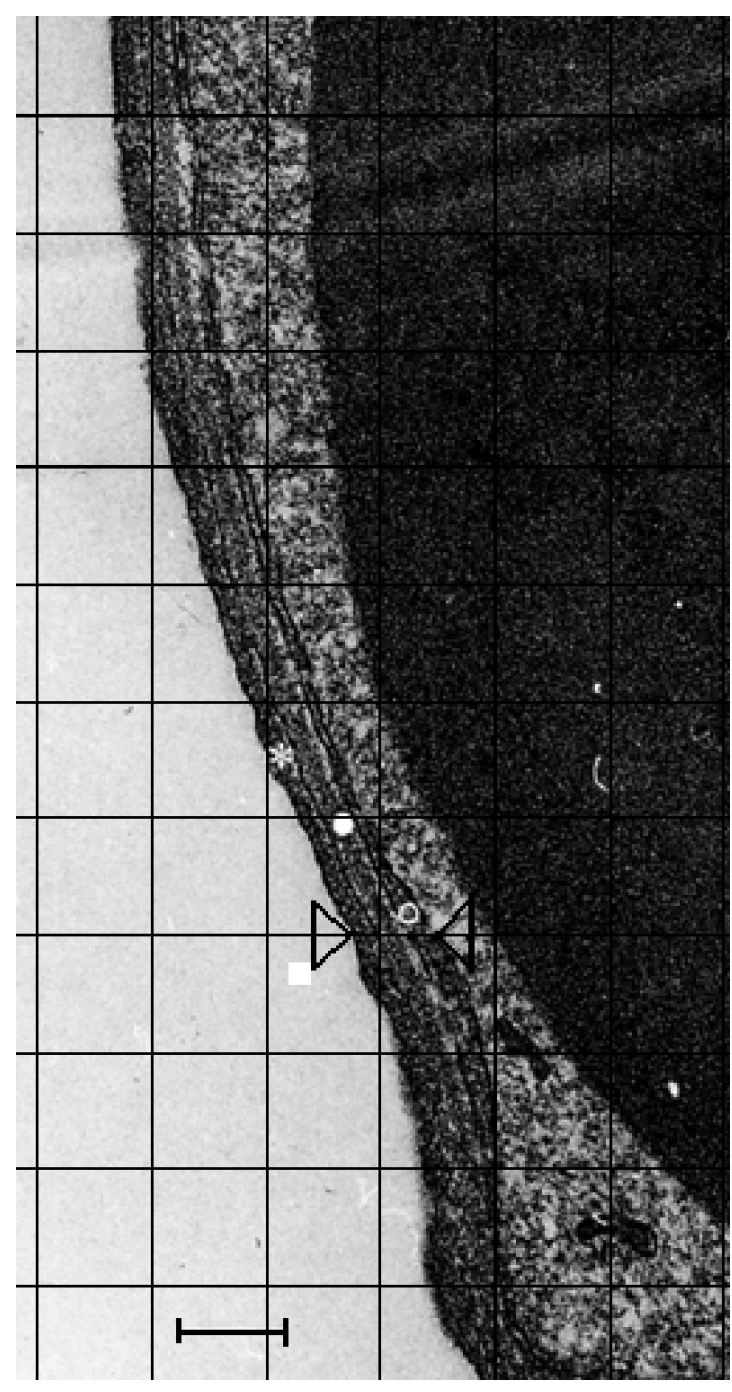

Fig. 2: Air-blood barrier of lung of Phyllotis darwini. With a square lattice grid to estimate the harmonic mean thickness of the air-blood barrier $\left(\tau_{\mathrm{h}}\right)$. Arrowheads mark an example of the points between which the thickness of the air-blood barrier was measured.

*: Epithelium, O: Basement membrane,

$\bullet$ : Endothelium. 20000X. Scale bar, $0.23 \mu \mathrm{m}$.

TABLE 1

Respiratory surface density $\left(\mathrm{AS}_{\mathrm{d}}\right)$ and harmonic mean thickness of the air-blood barrier $\left(\tau_{\mathrm{ht}}\right)$ in the studied species. All measurements are presented as average \pm 1 standard deviation

\begin{tabular}{lcc}
\hline & $\mathrm{AS}_{\mathrm{d}}\left(\mathrm{mm}^{-1}\right)$ & $\tau_{\mathrm{ht}}(\mu \mathrm{m})$ \\
\hline Z. auriculata & $394.99 \pm 27.3$ & $0.171 \pm 0.026$ \\
N. perdicaria & $230.57 \pm 2.57$ & $0.469 \pm 0.019$ \\
M. chiloensis & $257.18 \pm 11.18$ & $0.219 \pm 0.015$ \\
$P$. darwini & $145.19 \pm 9.2$ & $0.223 \pm 0.033$ \\
\hline
\end{tabular}




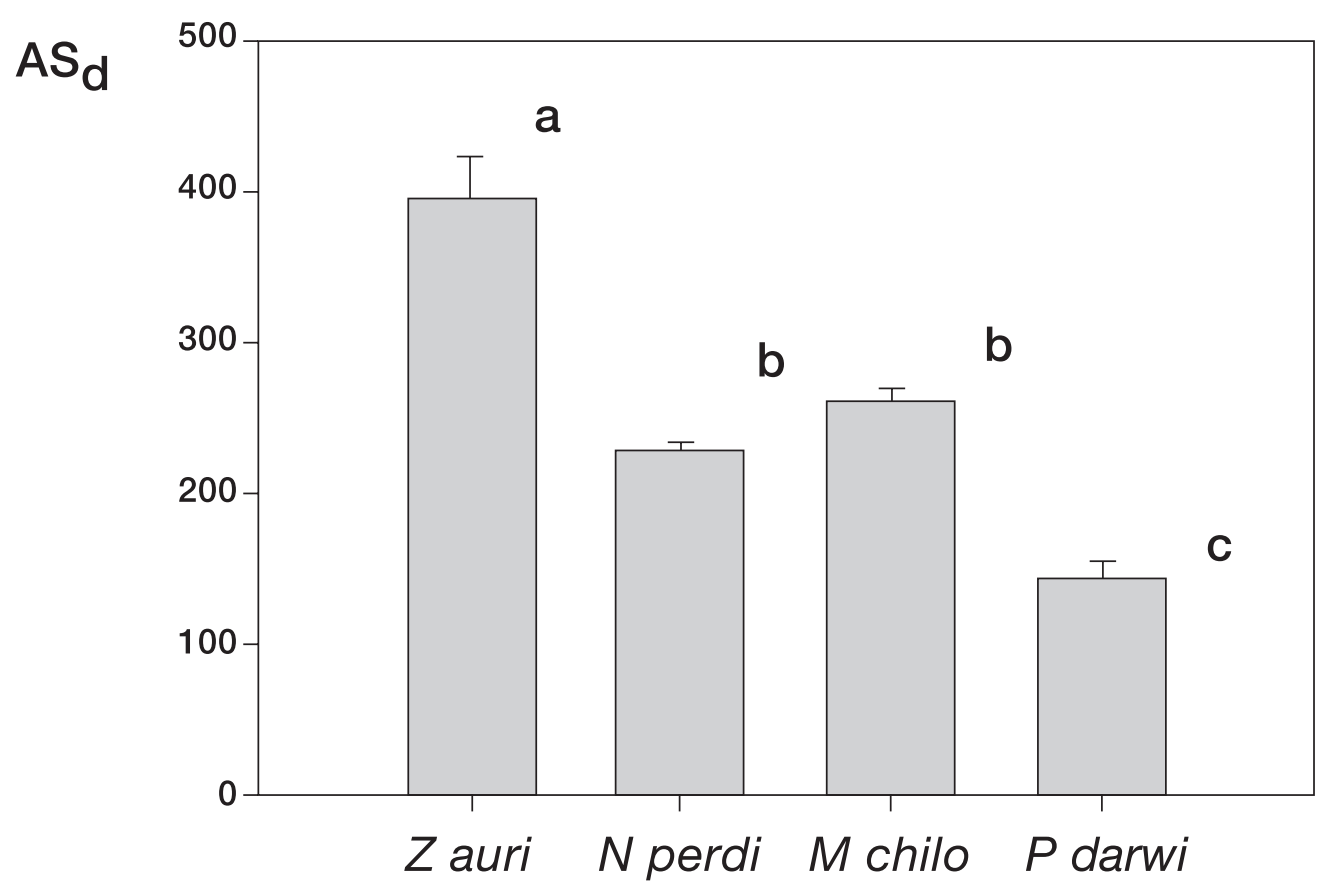

Fig. 3: Respiratory surface density $\left(\mathrm{AS}_{\mathrm{d}}\right)$ in the studied species. All measurements are presented as average \pm 1 standard deviation. Different letters indicate significant differences among species from the Tukey test.

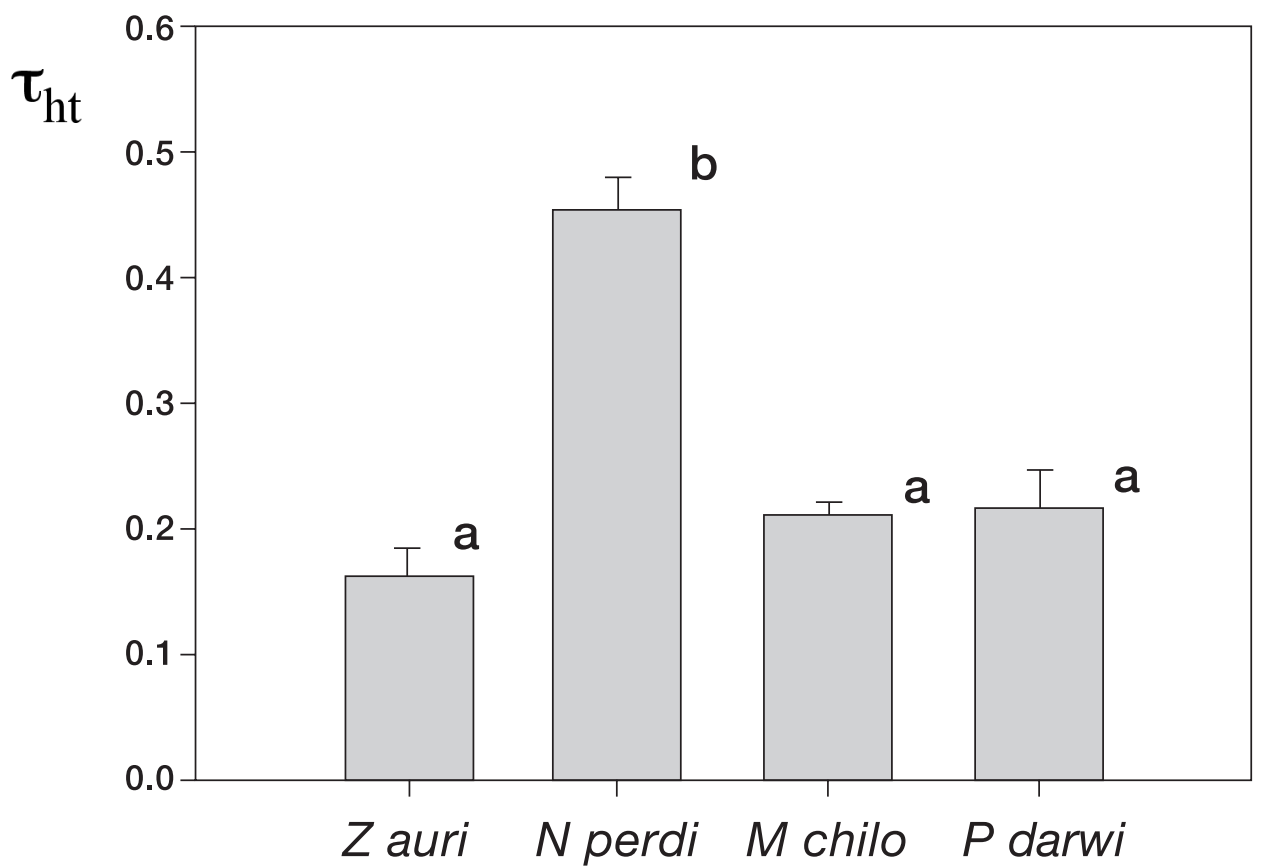

Fig 4: Harmonic mean thickness of the air-blood barrier $\left(\tau_{h t}\right)$ in the studied species. All measurements are presented as average \pm 1 standard deviation. Different letters indicate significant differences among species from the Tukey test. 
Of the four species studied in this work, the thinnest air-blood barrier (see Table 1) was found in the flying bird $Z$. auriculata. Its air-blood barrier was almost as thin as the Rock dove Columbia livia $(0.172 \mu \mathrm{m})$ (Maina, 2002a). The air-blood barrier of the bat $M$. chiloensis was also very thin $(0.219$ $\pm 0.01 \mu \mathrm{m})$, similar to other Vespertilionidae, such as Minopterus minor $(0.216 \mu \mathrm{m})$, and was in the range of several other bats, which have values between $0.202 \mu \mathrm{m}$ and $0.282 \mu \mathrm{m}$ (Maina et al., 1982; Maina and King, 1984). However, the rodent $P$. darwini also showed a thin airblood barrier $(0.223 \pm 0.03 \mu \mathrm{m})$. This value is surprising, because it is similar to the smallest known value in mammals, which is found in the shrew Suncus ethruscus (0.23 $\mu \mathrm{m})$, and similar to that of Mus musculus $(0.29 \mu \mathrm{m})$ (Gehr et al., 1981). Since $P$. darwini is not a very small mammal and probably does not have particularly high energetic requirements compared to other mammals (see Nespolo et al. 2001), we considered the possibility that the values measured were artificially diminished by the methods. In this case, the fixative and buffer used in this study would have produced a thickness barrier 6-24\% thinner than the combination used by Gehr et al. (1981, for small mammals (Maina, 2002a)). Even if we applied a correction to our value, we would obtain 0.236-0.277 $\mu \mathrm{m}$, which is still a very small value range. Perhaps the air-blood barrier observed in $P$. darwini is a consequence of its high Andean origin, which supposes the existence of higher energy requirements for thermoregulation and hence the possession of an optimized air-blood barrier, in spite of the fact that its current energy requirements are lower since its present range is a stable Mediterranean habitat (Engel et al. 1998)

The highest value of $\tau_{\mathrm{ht}}$ was found in the tinamou $N$. perdicaria $(0.469 \pm 0.02 \mu \mathrm{m})$. This is the first report to date of measurements of the lung parameters for any Tinamiform, so we cannot compare our results with those from closely related species. However, N. perdicaria has a thicker air-blood barrier than most bird species studied to date. Most birds have a lower $\tau_{\mathrm{ht}}$, in general ranging between 0.099 and $0.385 \mu \mathrm{m}$. Only Struthio camelus and Spheniscus humboldti have $\tau_{\mathrm{ht}}$ of roughly $0.5 \mu \mathrm{m}$ (Maina, 2002a). The value of $\tau_{\mathrm{ht}}$ in $N$. perdicaria approaches those of Galliformes species, which range from 0.318-0.346 $\mu \mathrm{m}$ in the domestic fowl Gallus gallus to $0.385 \mu \mathrm{m}$ in Meleagris gallopavo. The flightless domestic galliform species have relatively thicker air-blood barriers, lower respiratory surface areas and pulmonary diffusing capacities compared to species with higher energetic requirements (Maina, 2002a; 2002b). This may be also the case for $N$. perdicaria. Other members of Ratites have dissimilar thicknesses of the air-blood barrier, 0.530 um in Struthio camelus (Struthioformes) and $0.232 \mu \mathrm{m}$ in Dromaius novaehollandiae (Casuariiformes), suggesting that phylogenetic origin is not responsible.

The respiratory surface density showed strong differences between flying and "nonflying" species. The highest values were observed in the dove Z. auriculata (310.29 $\pm 17.5 \mathrm{~mm}^{-1}$ ) and the bat $M$. chiloensis $\left(202.03 \pm 7.1 \mathrm{~mm}^{-1}\right)$. Zenaida auriculata exhibits values in the range of other fastflying birds, such as Columba livia (302 $\left.\mathrm{mm}^{-1}\right)$ and several Passeriformes $(\approx 300$ $\mathrm{mm}^{-1}$ ) (Maina, 2002a). The respiratory surface density of the bat M. chiloensis was higher than those of the small shrews, 121 $\mathrm{mm}^{-1}$ on average (Gehr et al., 1981), and those of several bats spp. (see Maina et al., 1982). The running mammal $P$.darwini and the occasionally flying $N$. perdicaria showed low respiratory surface density. The former has values similar to other nonflying mammals, but $N$. perdicaria has a low value only comparable to the domestic Galliformes and great non-flying birds such as Struthio camelus and Dromaius novaehollandiae.

The thickness of the air-blood barrier and the respiratory surface density do not determine uniquely the oxygen diffusion capacity. Estimating lung volume from allometric relationships, considering 90 and $46 \%$ of lung volume as parenchymal volume in mammals and birds respectively (Maina, 2002a) and using a constant value for the Krogh's diffusion coefficient $\kappa=4.1$ $\cdot 10^{-8} \mathrm{~cm}^{2} / \mathrm{s} \cdot \mathrm{Pa}$ because this is not greatly 
influenced by temperature (Maina 2002a), we estimated the mass-specific oxygen diffusion capacity $\left(\mathrm{D}_{\mathrm{t}} \mathrm{O}_{2} / \mathrm{Mb}\right)$ for the studied species (Table 2). According to these estimations, the bat and the dove have much greater diffusion capacity than the other species.

During flight, the energetic requirements of bats are comparable to that of birds (Jurgens et al., 1981). Birds satisfy these requirements by means of morphological specializations, such as fine subdivision of exchange tissue and thinner air-blood barrier, among others. The respiratory surface density, a variable that denotes the relative size of the terminal gas exchange components, has been reported as substantially greater in the avian lung than in the lungs of bats and the non-flying mammals (Maina 2000a; 2002b). However, the respiratory surface density of the species studied in this work appears to be high in good flyers, the bat and dove spp., but not in the occasionally flying bird $N$. perdicaria. This finding suggests a differential morphometry in response to energetic demands.

Since bats achieve high oxygen consumption during flight (Norberg, 1987; Thomas, 1987) without cross-current or counter-current exchange systems, their lungs show other structural adaptations such as: 1) exceptionally large lungs (and hearts) (Jurgens et al., 1981; Canals et al., 2005 b), 2) relatively extensive mass specific surface area and 3) thin air-blood barrier, among others (Maina et al., 1982). The studied bat $M$. chiloensis has a large lung, about $0.058 \mathrm{~cm}^{3} / \mathrm{g}$ (Canals et al., 2005 b,c), while shrews and hummingbirds, the most metabolically active in their respective vertebrate classes, have average values of $0.03 \mathrm{~cm}^{3} / \mathrm{g}$ (Gehr et al., 1981) and $0.043 \mathrm{~cm}^{3} / \mathrm{g}$ (Maina et al., 1982), respectively. The estimated mass specific respiratory surface area of the bat was 2.8 times that of the dove, 4.1 times that of $P$. darwini and 4.8 times that of $N$. perdicaria. It was larger than the value reported for the small hummingbird Colibri coruscans, $87 \mathrm{~cm}^{2} / \mathrm{g}$ (Maina, 2002a), but smaller than that of the small bat Epomophorus wahlbergi, $138 \mathrm{~cm}^{2} / \mathrm{g}$ (Maina et al., 1991).

The estimated values for the oxygen diffusion capacity, $\mathrm{D}_{\mathrm{t}} \mathrm{O}_{2}$, confirm the same pattern: the highest values in the good fliers, the bat and the Eared dove, and the lowest value in the Chilean tinamou. The $\mathrm{D}_{\mathrm{t}} \mathrm{O}_{2}$ of $\mathrm{M}$. chiloensis was greater than that of Pipistrellus pipistrellus $\left(12.8 \times 10^{-6} \mathrm{mlO}_{2} /\right.$ $\mathrm{Pa} \mathrm{s} g$ ) and close to that of $E$. wahlbergi $\left(23.5 \times 10^{-6} \mathrm{mlO}_{2} / \mathrm{Pa} \mathrm{s} \mathrm{g}\right)$, these are two

Pulmonary diffusion parameters of studied species: $\mathbf{A S}_{\mathbf{d}}=$ Respiratory surface density; $\tau_{\mathbf{h t}}$ $=$ Harmonic mean thickness of the air-blood (tissue) barrier; $\mathbf{M}_{\mathbf{b}}=$ Body mass; $\mathbf{V}_{\mathbf{L}}=$ Lung volume estimated by allometry; $\mathbf{R A}=$ Respiratory area $\left(\mathrm{RA}=\mathrm{SA}_{\mathrm{d}} * \mathrm{~V}_{\mathrm{LE}}\right)$ where $\mathrm{V}_{\mathrm{LE}}$ is the exchange lung volume estimated as $90 \%$ of $\mathrm{V}_{\mathrm{L}}$ in mammals and $46 \%$ of $\mathrm{V}_{\mathrm{L}}$ in birds (see Maina, 2002a); ADF is an anatomic diffusing factor $\left(\mathrm{ADF}=\mathrm{AS}_{\mathrm{d}} / \tau_{\mathrm{ht}}\right) ; \mathbf{D}_{\mathbf{t O 2}}=$ Pulmonary morphometric diffusion capacity of the air-blood barrier $\left(\mathrm{D}_{\mathrm{tO} 2}=\mathrm{RA} * \mathrm{~K} / \tau_{\mathrm{ht}}\right)$. The Krogh's coefficient was considered as a constant $\kappa=4.1 \cdot 10^{-8} \mathrm{~cm}^{2} / \mathrm{s} \cdot \mathrm{Pa}$. All measurements and estimations are presented as average \pm 1 standard deviation.

\begin{tabular}{|c|c|c|c|c|c|c|c|}
\hline & $\mathrm{M}_{\mathrm{b}}(\mathrm{g})$ & $\mathrm{RA}\left(\mathrm{cm}^{2}\right)$ & $\mathrm{RA} / \mathrm{M}_{\mathrm{b}}\left(\mathrm{cm}^{2} / \mathrm{g}\right)$ & $\mathrm{V}_{\mathrm{L}}\left(\mathrm{cm}^{3}\right)$ & $V_{L} / M_{b}\left(\mathrm{~cm}^{3} / \mathrm{g}\right)$ & $\operatorname{ADF}\left(\mathrm{cm}^{-2}\right)\left(x 10^{7}\right)$ & $\begin{array}{c}\mathrm{D}_{\mathrm{t} 02} / \mathrm{M}_{\mathrm{b}} \\
\left(\mathrm{mlO}_{2} \mathrm{~s}^{-1} \mathrm{~Pa}^{-1} \mathrm{~g}^{-1}\right) \\
\left(\mathrm{x} 10^{-6}\right)\end{array}$ \\
\hline Z. auriculata & $141 \pm 1.55$ & $6860.57 \pm 574.8$ & $48.59 \pm 3,44$ & $3.77 \pm 0.06$ & $0.027 \pm 0.00005$ & $23.43 \pm 3.58$ & $11.81 \pm 1.79$ \\
\hline N. perdicaria & $398 \pm 11.7$ & $12009.55 . \pm 578.6$ & $30,14 \pm 0.39$ & $11.32 \pm 0.43$ & $0.028 \pm 0.00006$ & $4.92 \pm 0.25$ & $2.64 \pm 0.14$ \\
\hline M. chiloensis & $6 \pm 0.10$ & $833.33 \pm 38.2$ & $138.8 \pm 6.17$ & $0.36 \pm 0.01$ & $0.06 \pm 0.00007$ & $11.77 \pm 0.32$ & $26.0 \pm 0.69$ \\
\hline P. darwini & $75 \pm 4.96$ & $2514.13 \pm 470.6$ & $33.17 \pm 3.51$ & $1.91 \pm 0.17$ & $0.026 \pm 0.00015$ & $6.68 \pm 1.75$ & $6.26 \pm 1.68$ \\
\hline
\end{tabular}


small bats with very high $\mathrm{D}_{\mathrm{t}} \mathrm{O}_{2}$ (Maina et al., 1982; Maina and King, 1984). Z. auriculata showed a $\mathrm{D}_{\mathrm{t}} \mathrm{O}_{2}$ close to $C$. livia $\left(10.0 \times 10^{-6} \mathrm{mlO}_{2} / \mathrm{Pa} \mathrm{s} \mathrm{g}\right)$ and several other Columbiformes (Maina, 2002a). P. darwini showed a $\mathrm{D}_{\mathrm{t}} \mathrm{O}_{2}$ close to $M$. musculus $\left(4.2 \times 10^{-6} \mathrm{mlO}_{2} / \mathrm{Pa} \mathrm{s}\right.$ g) (Gehr et al., 1981) and $N$. perdicaria showed the lowest $\mathrm{D}_{\mathrm{t}} \mathrm{O}_{2}$, which is close to the domestic fowl and the ostrich, both representatives of non-flying birds.

Considering the allometric relationships for the total oxygen diffusion capacity from air to to red cells, $\mathrm{D}_{\mathrm{LO} 2}: D_{\mathrm{LO} 2}($ birds $)=7.19$ - $M_{b}^{0.9198} ; D_{L O 2}$ (bats) $=25.96 \cdot M_{b}^{0.6240}$ and $D_{\mathrm{LO} 2}($ nonflyingmammals $)=5.92 \cdot M_{b}^{0.9513}$, where $\mathrm{M}_{\mathrm{b}}$ is in grams and $\mathrm{D}_{\mathrm{LO} 2}$ in $\mathrm{mm}^{3} \mathrm{O}_{2}$ min $^{-1} \mathrm{mmHg}^{-1}$ and the observation that $\mathrm{D}_{\mathrm{LO} 2}$ is about $1 / 10$ of $\mathrm{D}_{\mathrm{t}} \mathrm{O}_{2}\left(\mathrm{D}_{\mathrm{LO} 2} / \mathrm{D}_{\mathrm{t}} \mathrm{O}_{2}\right.$ ratio $=$ $0.092 \pm 0.07$ in birds and $0.10 \pm 0.031$ in bats) (Canals et al., 2005a), we did estimate the expected $\mathrm{D}_{t} \mathrm{O}_{2}$ value for the species we studied. These values were $6.06 \times 10^{-6} \mathrm{mlO}_{2}$ $\mathrm{s}^{-1} \mathrm{~Pa}^{-1} \mathrm{~g}^{-1}$ for the dove; $5.57 \times 10^{-6} \mathrm{mlO}_{2} \mathrm{~s}^{-}$ ${ }^{1} \mathrm{~Pa}^{-1} \mathrm{~g}^{-1}$ for the Chilean tinamou; $16.69 \times 10^{-6}$ $\mathrm{mlO}_{2} \mathrm{~s}^{-1} \mathrm{~Pa}^{-1} \mathrm{~g}^{-1}$ for the bat and $6.01 \times 10^{-6}$ $\mathrm{mlO}_{2} \mathrm{~s}^{-1} \mathrm{~Pa}^{-1} \mathrm{~g}^{-1}$ for $P$. darwini. The values that we obtained represented $153.13 \%$; $37.14 \% ; 122.22 \%$ and $81.86 \%$ of those expected values respectively, reinforcing the idea that good flying species have greater oxygen diffusion capacities despite body mass differences.

In short, the studied species showed refinements in their morphometric lung parameters in response to energetic requirements associated mainly with their form of locomotion, rather than their phylogenetic origin. The air-blood barrier appears to be thin in most birds and small mammals, except those with low energetic requirements such as the Chilean tinamou. In the species we studied, the respiratory surface density appears to be the main factor responding to the energetic requirements of flight. However in the bats large lungs contribute to high oxygen diffusion capacity paralleling their high metabolic demand for oxygen. Since the context in which the interplay described in this work is allometric we would expect such interplay to hold true over a vast range of animals of different body weights.

\section{ACKNOWLEDGMENTS}

We thank Bradley Bakken and Lafayette Eaton for revising the English. This work was supported by the FONDECYT 1040649 grant to MCL.

\section{REFERENCES}

CANALS M, ATALA C, OLIVARES R, GUAJARDO F, FIGUEROA D, SABAT P, ROSENMANN M (2005a) Functional and structural optimization of the respiratory system of the bat Tadarida brasiliensis (Chiroptera, Molossidae): Does the airway geometry matter? J Exp Biol 208: 3987-3995

CANALS M, ATALA C, GROSSI B, IRIARTE-DÍAZ J (2005b) Relative size of hearts and lungs of small bats. Acta Chiropterologica 7: 65-72

CANALS M, OLIVARES R, ROSENMANN M (2005c) A radiographic method to estimate lung volume and its use in small mammals. Biol Res 38: 41-47

DUBACH M (1981) Quantitative analysis of the respiratory system of the house sparrow, budgerigar and violeteared hummingbird. Respir Physiol 46: 43-60

ENGEL SR, HOGAN HM, TAYLOR JF, DAVIS SK (1998) Molecular systematics and paleobiogeography of the South African Sigmodontine rodents. Mol Biol Evol 15: 35-49

GEHR P, MWANGI DK, AMMAN A, MALOIY GM, TAYLOR CR, WEIBEL ER (1981) Design of the mammalian respiratory system.V. Scaling morphometric diffusing capacity to body mass: wild and domestic animals. Respir Physiol 44: 61-86

JURGENS JD, BARTELS H, BARTELS R (1981) Blood oxygen transport and organ weight of small bats and small non-flying mammals. Resp. Physiol. 45: 243-260

MAINA J N (1998) The lungs of the flying vertebrates birds and bats: is their structure optimized for this elite mode of locomotion? In: Principles of animal design: The optimization and symmorphosis debate (E. R Weibel, C. R. Taylor and L. Bolis, eds.). Cambridge University Press. New York, EEUU. pp: 177-185

MAINA JN (2000) What it takes to fly: The structural and functional respiratory refinements in birds and bats. J Exp Biol 203: 3045-3064

MAINA JN (2002a) Some recent advances on the study and understanding of the functional design of the avian lung: morphological and morphometric perspectives. Biol Rev 77: 97-152

MAINA JN (2002b) Structure, function and evolution of the gas exchangers: comparative perspectives. J Anat 201: 281-304

MAINA JN, KING AS, KING DZ (1982) A morphometric analysis of the lung of a species of bat. Respir Physiol 50: $1-11$

MAINA JN, KING AS (1984) Correlations between structure and design of the bat lung: a morphometric study. J Exp Biol 111: 43-61

MAINA JN, THOMAS SP, HYDE DM (1991) A morphometric study of the lungs of different sized bats: correlations between structure and function of the chiropteran lung. Phil Trans R Soc Lond B 333: 31-50

MAINA JN, NATHANIEL C (2001) A qualitative and quantitative study of the lung of an ostrich, Struthio camelus. J Exp Biol 204: 2313-2330. 
NESPOLO RF, OPAZO JC, BOZINOVIC F (2001) Thermal acclimation and non-shivering thermognesis in three species of South American rodents: a comparison between arid and mesic habitats. J Arid Environ 48: 581-590

NORBERG UM (1987) Wing form and flight mode in bats. In: Recent advances in the study of bats (M. B. Fenton, P. Racey and M. V. Rayner, eds).Cambridge University Press. Cambridge, Inglaterra. pp: 43-56

NOVOA FF, RUIZ G, ROSENMANN M (2003) El oxígeno y la vida en alta altitud: Adaptaciones en vertebrados terrestres. In: Fisiología ecológica y evolutiva (F. Bozinovic, ed.). Ediciones Universidad Católica de Chile. Santiago, Chile. pp: 227-246

THOMAS, SP (1987) The physiology of bat flight. In: Recent advances in the study of bats (M. B. Fenton, P.
Racey and M. V. Rayner, eds).Cambridge University Press. Cambridge, England. pp: 75-99

VITALI SD, RICHARDSON KC (1998) Evaluation of pulmonary volumetric morphometry at the light and electron microscopy level in several species of passerine birds. J Anat 193: 573-580

WEIBEL ER (1970/71) Morphometric estimation of pulmonary diffusion capacity. I. Model and method. Respir Physiol 11: 54-75

WEIBEL ER, KNIGHT BW (1964) A morphometric study on the thickness of the pulmonary air-blood barrier. J Cell Biol 21: 367-384

WEIBEL ER, TAYLOR CR, HOPPELER H (1991) The concept of symmorphosis: a testable hypothesis of structure-function relationship. Proc Natl Acad Sci 88: 10357-10361 
